\title{
BMJ Open Comparison of the pathways of care and life courses between first-time ST- elevation myocardial infarction (STEMI) and STEMI with prior MI: findings from the OSCAR registry
}

\author{
Laurie Fraticelli (D) ,1,2 Olivier Kleitz, ${ }^{1}$ Clément Claustre, ${ }^{1}$ Nicolas Eydoux, ${ }^{1}$ \\ Alexandra Peiretti, ${ }^{1}$ Karim Tazarourte, ${ }^{3,4}$ Eric Bonnefoy-Cudraz, ${ }^{5}$ Claude Dussart, ${ }^{2}$ \\ Carlos El Khoury, ${ }^{4,6}$ the RESCUe Research Group
}

To cite: Fraticelli L, Kleitz 0 , Claustre C, et al. Comparison of the pathways of care and life courses between firsttime ST-elevation myocardial infarction (STEMI) and STEMI with prior Ml: findings from the OSCAR registry. BMJ Open 2020;10:e038773. doi:10.1136/ bmjopen-2020-038773

- Prepublication history for this paper is available online. To view these files, please visit the journal online (http://dx.doi. org/10.1136/bmjopen-2020038773).

Received 23 March 2020 Revised 29 September 2020 Accepted 20 0ctober 2020

Check for updates

(C) Author(s) (or their employer(s)) 2020. Re-use permitted under CC BY-NC. No commercial re-use. See rights and permissions. Published by BMJ.

For numbered affiliations see end of article.

Correspondence to Dr Laurie Fraticelli; I.fraticelli@resuval.fr

\section{ABSTRACT}

Objectives We hypothesised that patients having experienced one coronary event in their life were susceptible to present differences in their pathways of care and within 1 year of their life courses. We aimed to compare pathways between first-time ST-elevation myocardial infarction (STEMI) and STEMI with prior myocardial infarction (MI).

Design A retrospective observational study based on the Observatoire des Syndromes Coronariens Aigus du réseau RESCUe (OSCAR) registry collecting all suspected STEMI from 10 percutaneous coronary intervention centres in France.

Setting All patients with STEMI from 2013 to 2017 were included ( $\mathrm{N}=6306$ with 5423 first-time STEMI and 883 STEMI with prior MI). We provided a matching analysis by propensity score based on cardiovascular risk factors. Participants We defined first-time STEMI as STEMI occurring at the inclusion date, and STEMI with prior MI as STEMI with a history of MI prior to the inclusion date. Results Patients with first-time STEMI and patients with STEMI with prior MI were equally treated during hospitalisation and at discharge. At 12 months, patients with first-time STEMI had a lower adherence to BASIC treatment (ie, beta-blocker, antiplatelet therapy, statin and converting enzyme inhibitor) ( $48.11 \%$ vs $58.58 \%$, $\mathrm{p}=0.0167$ ), more frequently completed the cardiac rehabilitation programme $(44.33 \%$ vs $31.72 \%, p=0.0029)$, more frequently changed their lifestyle behaviours; more frequently practiced daily physical activity $(48.11 \%$ vs $35.82 \%, p=0.0043)$ and more frequently stopped smoking at admission $(69.39 \%$ vs $55.00 \%, p=0.0524)$. The estimated mortality was higher for patients with STEMI with prior Ml at 1 month $(p=0.0100), 6$ months $(p=0.0500)$ and 1 year $(\mathrm{p}=0.0600)$.

Conclusions We provided an exhaustive overview of the real-life clinical practice conditions of STEMI management. The patients with STEMI with prior MI presented an optimised use of prehospital resources, which was probably due to their previous experience, and showed a better adherence to drug therapy compared with patients with first-time STEMI.

\section{Strengths and limitations of this study}

- The Observatoire des Syndromes Coronariens Aigus du réseau RESCUe (OSCAR) registry provided an exhaustive overview of real-life clinical practices conditions.

- We enrolled 5423 first-time ST-elevation myocardial infarction (STEMI) and 883 STEMI with prior MI.

- We provided a matching analysis by fitting a propensity score on cardiovascular risk factors.

- A strength of this study was that $88.52 \%$ of vital status was known at 1 year post-discharge.

- A limitation of this study was that the key lifestyle interventions at 1 year were collected by the general practitioner for only $33.54 \%$ of enrolled patients.

Trial registration number Commission Nationale de I'Informatique et des Libertés (number 2013090 v0).

\section{BACKGROUND}

The recently declining mortality of patients with myocardial infarction (MI) is attributable to the wide diffusion of early reperfusion techniques, ${ }^{1}$ modern antithrombotic therapies and secondary prevention. ${ }^{2}$ Despite these major advances, mortality remains substantial with approximately $10 \%$ of mortality rate at 12 months in angiography registries ${ }^{34}$, and in-hospital mortality rates at $4 \%-12 \%$ observed in the national registries of the European Society of Cardiology (ESC) countries. ${ }^{5}$ Additionally, reinfarction carried a strong, significant and independent risk of subsequent cardiac death. ${ }^{6}$ Regardless of the curative and preventive treatments, the literature has identified individual predictors of reinfarction, such as advanced age, arterial hypertension, hyperglycaemic, dyslipidaemia, renal failure, alteration of left 
ventricular ejection fraction (LVEF), history of ischaemic stroke,${ }^{78}$ active smoking and certain genotypes. ${ }^{9}$ Whereas the management of the acute phase is essential in shortterm outcomes, ${ }^{10}$ the key lifestyle interventions following MI, as depicted by the European guidelines, ${ }^{11}$ give the patient a central role in their own management. The literature has shown that a low adherence to drug therapy and behavioural interventions were associated with worse outcomes. ${ }^{12}$ It is estimated that only $14 \%-35 \%$ of heart attack survivors participate in secondary prevention programmes, and $70 \%$ of suitable patients did not receive dedicated interventions for risk factor reduction. ${ }^{13}$ We hypothesised that despite the absence of differences in management in the acute phase between the first-time ST-elevation MI (STEMI) and STEMI with prior MI, the life courses within 12 months post-STEMI may differ. This study aimed to compare the pathways of care in the acute phase and the life courses within 12 months between firsttime STEMI and STEMI with prior MI.

\section{METHODS}

\section{Data source}

Since 2010, the Réseau Cardiologie Urgences (RESCUe) network has gathered emergency physicians and cardiologists from 10 percutaneous coronary intervention (PCI) centres around common guidelines. Covering a population of 3 million inhabitants in the Rhône-Alpes region of France, the prospective observational Observatoire des Syndromes Coronaires Aigus du réseau RESCUe (OSCAR) registry reports all patients with persistent chest pain and ST-segment elevation $\geq 2 \mathrm{~mm}$ in two contiguous leads, with no limitations with respect to age or delay in treatment. The monitoring of clinical research technicians guaranteed the quality and completeness of data, which is regularly tested by cross-checking the regional medico-administrative data. Since 2009, data have been at least $85 \%$ complete. ${ }^{14}$ All the participants gave oral informed consent. We used the Strengthening the Reporting of Observational Studies in Epidemiology cohort reporting guidelines. ${ }^{15}$

\section{Patient and Public Involvement}

Patients or the public were not involved in the design, or conduct, or reporting, or dissemination plans of the research.

\section{Collected data}

Patients were enrolled by prehospital emergency medical services (EMS) or the emergency department (ED). They received an individual information notice in accordance with the French legislation and gave their oral consent to participate in the data collection. At 12 months after discharge, the patient or his relatives were contacted by phone to collect possible new cardiac events, their vital status and adherence to the BASIC treatment (ie, beta-blocker, antiplatelet therapy, statin and converting enzyme inhibitor). For this study, the patients have not been re-contacted; all the information used in this study was derived from data collection in the observational register.

Collected data comprised cardiovascular history at admission, regular medications, prehospital delays and hospital management. We referred to BASIC treatment as the optimal drug therapy recommended by the ESC 2017 guidelines ${ }^{11}$ which is a combination of a beta-blocker, antiplatelet therapy, statin and converting enzyme inhibitor. After hospital discharge, a phone operator contacted patients or their relatives at 12 months to collect adherence to BASIC treatment. At 12 months, a survey was sent by mail to general practitioners (GPs) to collect additional information about healthy lifestyle behaviours (including cessation of smoking, advice about diet and weight control, encouraged physical activity at least $30 \mathrm{~min} /$ day, participation in a cardiac rehabilitation programme and monitoring of lipid and glucose at 3 months and/or 6 months) and vital status (cause and date of death). The data from the GPs were retained if any discrepancies were reported between the follow-up by phone and the survey.

\section{Population selection}

All patients with STEMI as a final diagnosis were included. We restricted the study period from 1 January 2013 to 31 December 2017, considering a delay of 2 years after the French marketing authorisation for ticagrelor and 1 year after European recommendations favouring P2Y ${ }_{12}$ inhibitors at discharge, such as clopidogrel. ${ }^{16}{ }^{17}$ A first-time STEMI was defined as a STEMI occurring at the inclusion date, without history of coronaropathy disease in the past, and STEMI with prior MI was defined as a STEMI with a history of MI up to 1 year before the inclusion date (figure 1).

\section{Outcomes: measured indicators}

The comparison of the pathways of care between firsttime STEMI and STEMI with prior MI was based on recommended quality indicators ${ }^{18}$ as follows: (1) proportion of patients reperfused within 12 hours from the onset of symptoms to diagnosis, (2) proportion of patients with timely reperfusion, (3) proportion of patients with adequate $\mathrm{P}_{2} \mathrm{Y}_{12}$ inhibition at discharge and/or with dual antiplatelet therapy, (4) proportion of patients discharged on statins, (5) proportion of patients with heart failure discharged on an Angiotensin Converting Enzyme Inhibitor (ACEI) or Angiotensin Receptor Blocker (ARB) if intolerant of an ACEI and (6) proportion of patients with heart failure discharged on beta-blockers. The comparison of life courses between first-time STEMI and STEMI with prior MI was based on the key lifestyle interventions mentioned in the 2017 ESC guidelines, including: (1) the 12-month adherence to BASIC treatment, (2) the follow-up of the cardiac rehabilitation programme, (3) daily physical activity, (4) smoking cessation for active smokers, (5) balanced diet for overweight, diabetes and dyslipidaemic patients and (6) lipid and glucose monitoring at 3 months and/or 6 months. 


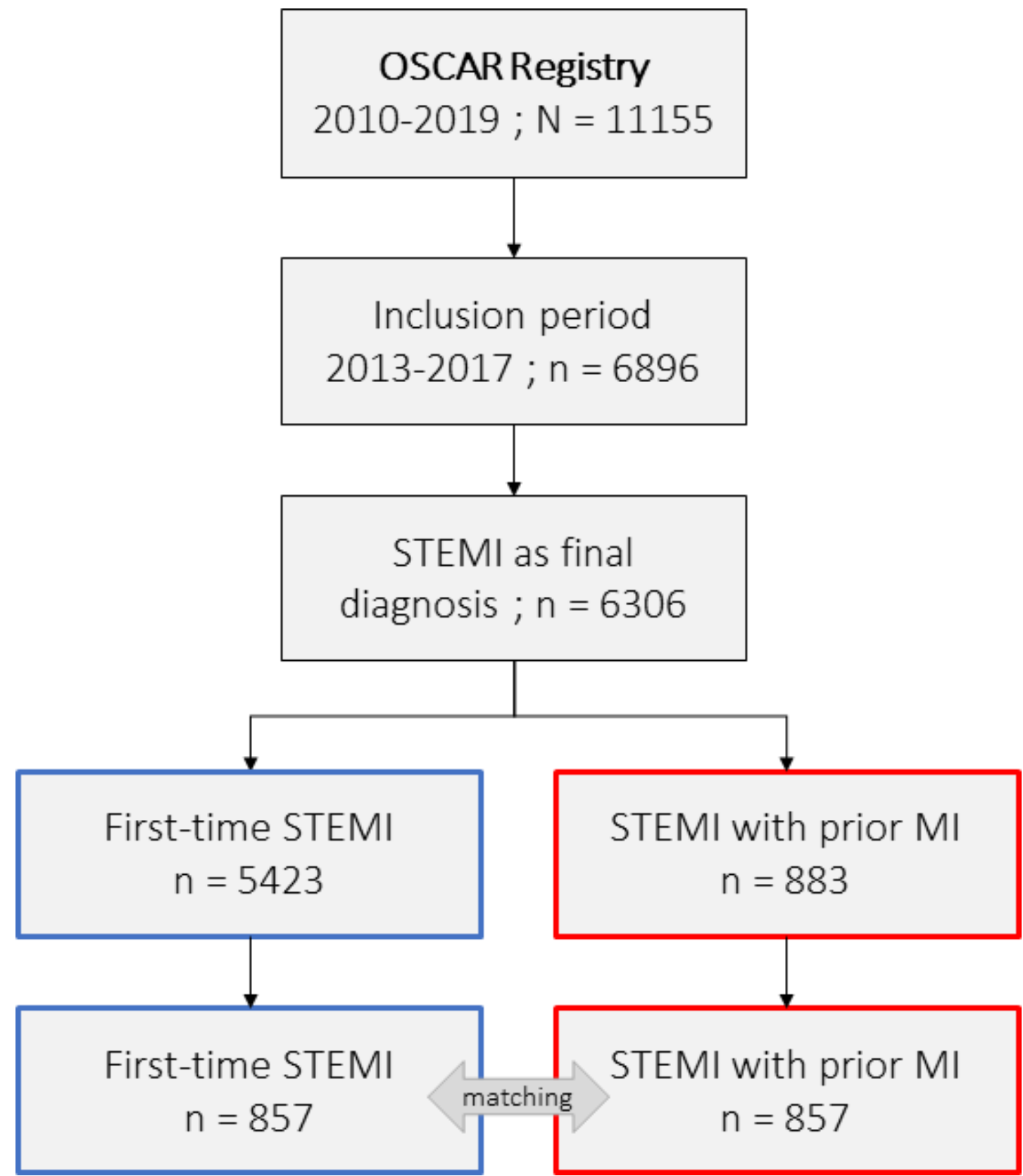

Figure 1 Flowchart of the study population from the OSCAR, registry of acute coronary syndromes. MI, myocardial infarction; OSCAR, Observatoire des Syndromes Coronariens Aigus du réseau RESCUe; STEMI, ST-elevation myocardial infarction.

\section{Statistical analysis}

Categorical data are presented as frequencies and percentages, and continuous data are presented as medians and IQRs (first and third quartiles). The Results section mentions in brackets the observed data for firsttime STEMI and then for STEMI with prior MI. Bivariate statistical comparisons were performed with Pearson's $\chi^{2}$ test for categorical data and the non-parametric Wilcoxon rank test for continuous data, which is labelled as 'unadjusted $p$ value'. A probability value, $p$, of less than 0.05 was considered significant. We also provided a matching analysis by fitting a propensity score. The propensity score was computed by logistic regression using 6306 patients $(0$ : first-time STEMI vs 1: STEMI with prior MI, as response variables). The explanatory variables were age, sex, active smoking, hypertension, diabetes, dyslipidaemia, renal failure and being overweight. The matching was achieved using the nearest neighbour method with a specified calliper distance of $10 \%$ of the propensity score's SD. We excluded $223(3.54 \%)$ patients, with $197(3.63 \%)$ first-time STEMI and 26 (2.94\%) STEMI with prior MI, because of missing values. The final matched population comprised 1714 patients (857 first-time STEMI vs 857 STEMI with prior MI). The balance between matched samples was assessed using standardised mean differences before and after matching (figure 2). We performed the McNemar's Khi test for categorical variables and the nonparametric Wilcoxon sign test for continuous variables to 


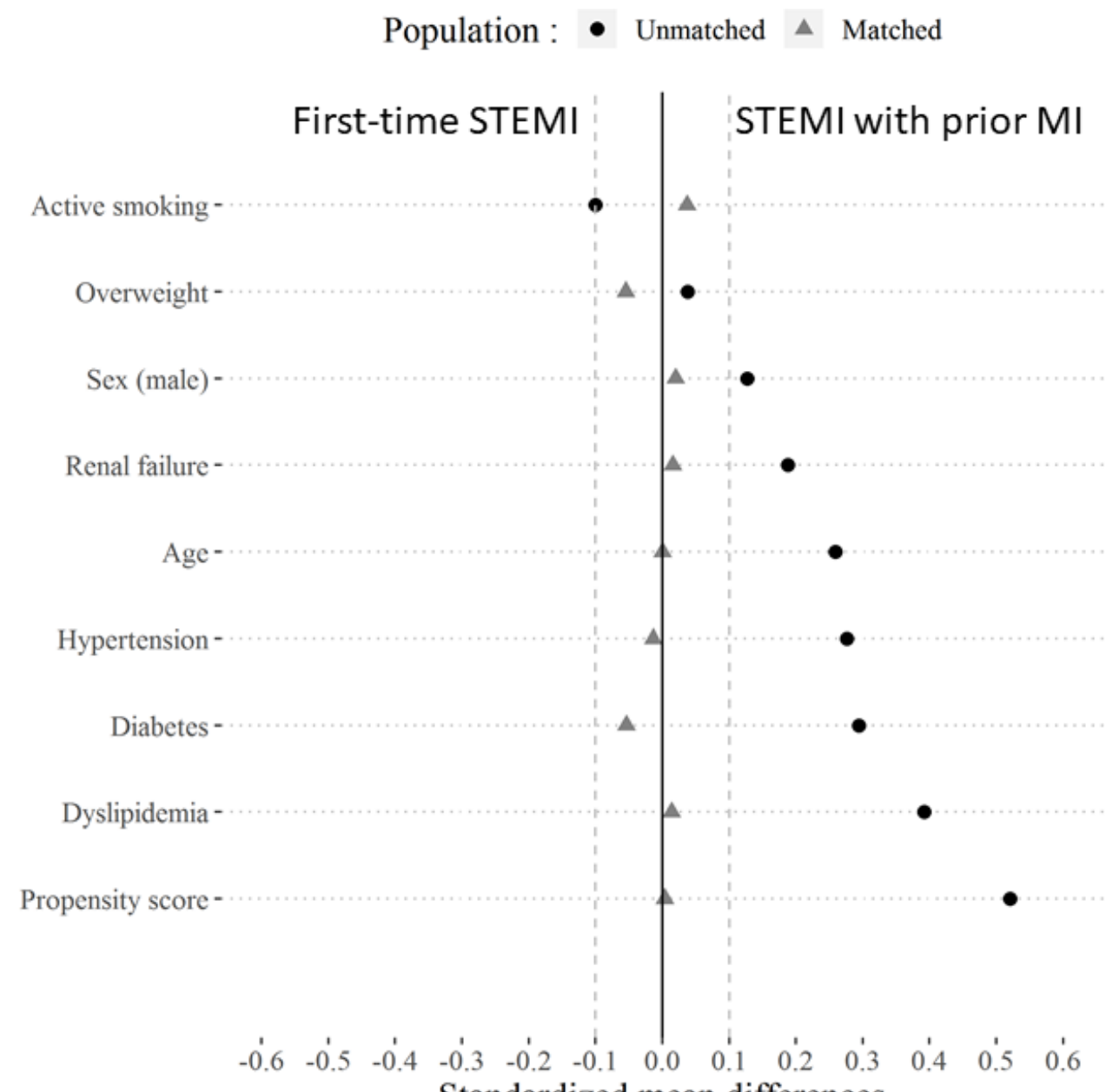

Standardized mean differences

Figure 2 Standardised mean differences before and after propensity score matching. MI, myocardial infarction; STEMI, STelevation myocardial infarction.

compare adjusted pairs, which was labelled as 'adjusted $p$ value'. We provided a Kaplan-Meier survival curve for comparison of mortality rates at 1 month, 6 months and 1 year post-qualifying ECG. For testing the equality of survival curves in propensity score matched samples, we performed stratified log-rank tests. ${ }^{19}$ We mentioned the adjusted results alongside the results section, except for the section's baseline characteristics.

\section{RESULTS}

\section{Baseline characteristics}

We enrolled 6306 patients with 5423 first-time STEMI and 883 STEMI with prior MI. Patients with first-time STEMI were younger than patients with STEMI with prior MI (62 years old (53-74) vs 67 years old (56-78), $\mathrm{p}<0.0001)$ and presented fewer cardiovascular risk factors at admission, including hypertension $(40.90 \%$ vs $54.81 \%, \mathrm{p}<0.0001)$, diabetes $(15.80 \%$ vs $28.88 \%, \mathrm{p}<0.0001)$, dyslipidaemia (27.84\% vs $46.77 \%, \mathrm{p}<0.0001)$ and renal failure $(20.47 \%$ vs $28.99 \%, \mathrm{p}<0.0001$ ) (table 1 ). Overweight patients were represented equally in both groups $(38.80 \%$ vs $40.77 \%$, $\mathrm{p}=0.2817$ ). Women were older than men (72 years old $(59-82)$ vs 60 years old $(51-70), \mathrm{p}<0.0001)$ in the first-time
STEMI group. Reinfarction occurred later in life for women compared with men (78 years old (64.5-87) vs 65 years old (55-76), $\mathrm{p}<0.0001)$. There was also no difference regarding heart failure (Killip score $\geq 2) \quad(9.98 \%$ vs $15.29 \%, \mathrm{p}<0.0001)$, cardiogenic shock at admission (Killip score $=4)(1.07 \%$ vs $1.25 \%, p=0.7700)$ and cardiac arrest $(6.88 \%$ vs $5.89 \%, \mathrm{p}=0.3102)$.

\section{Delays and reperfusion strategy}

The following results were presented after matching analysis. Patients with STEMI with prior MI more frequently called the medical dispatch centre $(\mathrm{p}<0.0001)$ and were more frequently managed by EMS $(\mathrm{p}<0.0001)$ compared with patients with first-time STEMI (table 2). Once in the pathways of care, the delays from symptom to ECG were comparable whether patients were managed by EMS $(p=0.2420)$ or arrived directly to the ED $(p=0.0609)$. When patients arrived directly to the ED, the delay from symptom to admission was longer for patients with firsttime STEMI $(\mathrm{p}=0.0347)$. The patients with first-time STEMI received more PCI $(\mathrm{p}=0.0049)$. Among patients with PCI, the delay from ECG to reperfusion was similar between both groups $(p=0.7339)$, as well as the LVEF $(\mathrm{p}=0.0954)$. 
Table 1 Baseline characteristics at admission of first-time STEMI and STEMI with prior MI

\begin{tabular}{|c|c|c|c|}
\hline & $\begin{array}{l}\text { First-time STEMI } \\
\mathrm{n}=5423\end{array}$ & $\begin{array}{l}\text { STEMI with prior MI } \\
\mathrm{n}=883\end{array}$ & $\begin{array}{l}\text { Unadjusted } \\
\text { p value }\end{array}$ \\
\hline Age $^{*}$ (years) & $62(53-74)$ & $67(56-78)$ & $<0.0001$ \\
\hline Age $^{*}$ (years) & $60(51-70)$ & $65(55-76)$ & $<0.0001$ \\
\hline Women* & $1397(25.76 \%)$ & $183(20.72 \%)$ & 0.0016 \\
\hline Personal coronaropathy & $0(0.00 \%)$ & $866(98.07 \%)$ & $x$ \\
\hline Active smoking at admission* & $2101(38.74 \%)$ & $300(33.98 \%)$ & 0.0076 \\
\hline Hypertension* & $2218(40.90 \%)$ & $484(54.81 \%)$ & $<0.0001$ \\
\hline Diabetes* $^{*}$ & $857(15.80 \%)$ & $255(28.88 \%)$ & $<0.0001$ \\
\hline \multicolumn{4}{|l|}{ Regular medications } \\
\hline Anticoagulant therapy & $129(2.38 \%)$ & $63(7.13 \%)$ & $<0.0001$ \\
\hline BASIC treatment : & $0(0.00 \%)$ & $178(20.16 \%)$ & $x$ \\
\hline Beta-blockers & 507 (9.35\%) & $454(51.42 \%)$ & $<0.0001$ \\
\hline Antiplatelet therapy & $556(10.25 \%)$ & $665(75.31 \%)$ & $<0.0001$ \\
\hline Statins & $680(12.54 \%)$ & $503(56.96 \%)$ & $<0.0001$ \\
\hline Converting enzyme inhibitor & $467(8.61 \%)$ & 348 (39.41\%) & $<0.0001$ \\
\hline
\end{tabular}

*Variables included for the propensity score.

BMI, body mass index; MI, myocardial infarction; STEMI, ST-elevation myocardial infarction.

\section{Pathways of care in the acute phase}

Even though both groups were equally treated with primary PCI $(\mathrm{p}=0.2293)$, we observed a lower proportion of stenting among STEMI with prior MI $(\mathrm{p}<0.0001)$. The initial observation of thrombolysis in MI grade flow 0 were similar between the two groups $(\mathrm{p}=0.9169)$, with complete reperfusion $(p=0.8391)$. During hospitalisation, patients with first-time STEMI and patients with STEMI with prior MI were equally treated with adequate $\mathrm{P}_{2} \mathrm{Y}_{12}$ inhibition (96.74\% vs $95.14 \%, \mathrm{p}=0.5322)$. The prescriptions of $\mathrm{P}_{2} \mathrm{Y}_{12}$ inhibitors at discharge were different between the groups for ticagrelor $(55.71 \%$ vs $43.26 \%, \mathrm{p}<0.0001)$ and clopidogrel $(15.10 \%$ vs $23.33 \%, \mathrm{p}<0.0001)$, but the difference was not significant for prasugrel $(12.26 \%$ vs $9.06 \%$, $\mathrm{p}=0.0713$ ).

At discharge, patients were equally treated with statins (95.29\% vs $91.88 \%, p=0.0872)$, ACEI (92.31\% vs $88.46 \%$, $\mathrm{p}=1)$ and beta-blockers among patients with heart failure (93.99\% vs $92.27 \%, p=0.4795)$ and dual antiplatelet therapy $(95.99 \%$ vs $94.64 \%, \mathrm{p}=0.6583)$. We observed a higher in-hospital mortality among patients with STEMI with prior MI $(\mathrm{p}=0.0360)$.

\section{Life courses within 12 months of follow-up}

Concerning the life courses within 1 year after discharge, we observed only $33.54 \%$ of follow-up by the GP, with no significant difference in the follow-up proportions between the groups $(33.98 \%$ vs $30.80 \%, \mathrm{p}=0.0691)$. At 12 months, the first-time STEMI group presented a lower adherence to BASIC treatment compared with the STEMI with prior MI group ( $48.11 \%$ vs $58.58 \%, \mathrm{p}=0.0167$ ) (figure 3 ). The first-time STEMI group also more frequently completed the cardiac rehabilitation programme $(44.33 \%$ vs $31.72 \%, \mathrm{p}=0.0029)$, presented better adherence to the recommended lifestyle behaviours with the practice of a daily physical activity (48.11\% vs $35.82 \%, \mathrm{p}=0.0043)$ and stopped smoking (for active smokers reported at admission) $(69.39 \%$ vs $55.00 \%, \mathrm{p}=0.0524)$ compared with the STEMI with prior MI group. We did not observe differences between first-time STEMI and STEMI with prior MI with regard to a balanced diet for overweight, diabetes and dyslipidaemic patients $(72.82 \%$ vs $67.55 \%, \mathrm{p}=0.3023)$ and lipid and glucose monitoring at 3 months and/or 6 months $(92.78 \%$ vs $88.43 \%, \mathrm{p}=0.1045)$.

The vital status at 1 year was known for $88.70 \%$ of the first-time STEMI and $87.43 \%$ of the STEMI with prior MI $(p=0.2991)$. The mortality estimated by the KaplanMeier estimator was higher for patients with STEMI with prior MI compared with patients with first-time STEMI (figure 4$)$ at 1 month $(6.7 \%(5.0 \%-8.4 \%)$ vs $10.3 \%(8.2 \%$ $12.4 \%), \mathrm{p}=0.0100), 6$ months $(8.3 \%(6.4 \%-10.1 \%)$ vs $11.4 \%(9.1 \%-13.5 \%), \mathrm{p}=0.0500)$ and 1 year $(9.7 \%(7.6 \%-$ $11.7 \%)$ vs $13.0 \%(10.6 \%-15.3 \%), p=0.0600)$. 
Table 2 Management delays of first time STEMI and STEMI with prior MI groups in the acute phase (delays in minutes) and reperfusion strategy

$\begin{array}{lll}\substack{\text { First-time STEMI } \\ \mathrm{n}=5423} & \begin{array}{l}\text { STEMI with prior MI } \\ \mathrm{n}=883\end{array} & \begin{array}{l}\text { Adjusted } \\ \mathrm{p} \text { value }\end{array}\end{array}$

LVEF* $^{*}$

\begin{tabular}{|c|c|c|c|}
\hline LVEF $<30$ & 179 (3.30\%) & 39 (4.42\%) & 0.4497 \\
\hline $30 \geq \operatorname{LVEF}>50$ & 2005 (36.97\%) & $359(40.66 \%)$ & 0.5506 \\
\hline LVEF $\geq 50$ & 2757 (50.84\%) & 389 (44.05\%) & 0.2971 \\
\hline Call to medical dispatch centre & $3001(55.34 \%)$ & $591(66.93 \%)$ & $<0.0001$ \\
\hline Management by EMS & 2827 (52.13\%) & $548(62.06 \%)$ & $<0.0001$ \\
\hline Symptom-call & $50(18 ; 136)$ & $50(20 ; 120)$ & 0.1262 \\
\hline Call-ECG & $29(21 ; 40)$ & $29(21 ; 39)$ & 0.4891 \\
\hline Symptom-ECG & $88(53 ; 190)$ & $84.5(53 ; 159)$ & 0.2420 \\
\hline Admission to ED & $2596(47.87 \%)$ & 335 (37.94\%) & $<0.0001$ \\
\hline Without $\mathrm{PCl}$ centre & $1749(67.37 \%)$ & $191(57.01 \%)$ & 0.0090 \\
\hline Prehospital fibrinolysis & $88(5.03 \%)$ & $6(3.14 \%)$ & $\mathrm{x}$ \\
\hline Symptom-admission & $168(87-516)$ & $153.5(84.5-373)$ & 0.0347 \\
\hline Admission-ECG & $14(6-38)$ & $12(5.25-36)$ & 0.7383 \\
\hline Symptom-ECG & $207(107-576)$ & $191(100.5-426)$ & 0.0609 \\
\hline \multicolumn{4}{|l|}{ Reperfusion strategy } \\
\hline Fibrinolysis & $161(2.97 \%)$ & $21(2.38 \%)$ & 0.4292 \\
\hline Coronarography & 5397 (99.52\%) & 879 (99.55\%) & 1 \\
\hline Realised PCl & $5082(94.16 \%)$ & 794 (90.33\%) & 0.0049 \\
\hline Primary PCl & $4930(97.01 \%)$ & 778 (97.98\%) & 0.2293 \\
\hline ECG-reperfusion & 103(78;149) & $102(79 ; 149)$ & 0.7339 \\
\hline ECG-reperfusion $<90 \mathrm{~min}$ & $1657(32.61 \%)$ & $262(33.00 \%)$ & 0.7520 \\
\hline Stenting & $4160(81.86 \%)$ & $540(68.01 \%)$ & $<0.0001$ \\
\hline Bypass surgery (programmed or emergency) & $153(2.82 \%)$ & $27(3.06 \%)$ & 1 \\
\hline Initial TIMI grade 0 & $3270(60.30 \%)$ & 535 (60.59\%) & 0.9169 \\
\hline Final TIMI grade 3 & $4549(83.88 \%)$ & $694(78.60 \%)$ & 0.8391 \\
\hline \multicolumn{4}{|l|}{ Short-term status at discharge } \\
\hline Alive patients & $5152(95.00 \%)$ & $820(92.87 \%)$ & 0.0360 \\
\hline Discharged home & $3707(71.95 \%)$ & $587(71.59 \%)$ & 0.3534 \\
\hline Within 48 hours & $1273(34.34 \%)$ & 185 (31.52\%) & 0.6600 \\
\hline Critical care & $198(3.84 \%)$ & $33(4.02 \%)$ & 1 \\
\hline Other services & $1243(24.13 \%)$ & 199 (24.27\%) & 0.2791 \\
\hline Unknown & $4(0.08 \%)$ & $1(0.12 \%)$ & $\mathrm{x}$ \\
\hline In-hospital mortality & 271 (5.00\%) & 63 (7.13\%) & 0.0360 \\
\hline
\end{tabular}

ED, emergency department; EMS, emergency medical services; LVEF, left ventricular ejection fraction; MI, myocardial infarction; PCI, percutaneous coronary intervention; STEMI, ST-elevation myocardial infarction; TIMI, thrombolysis in myocardial infarction.

New cardiac event within 12 months follow-up for the firsttime STEMI

Among the first-time STEMI, we observed $3.45 \%$ patients with a new cardiac event during the 1-year follow-up $(187 / 5423)$. We did not observe any differences in the secondary prevention programme between first-time STEMI that experienced a cardiac event during follow-up and those who did not: $\mathrm{p}=0.1247$ for daily physical activity, $\mathrm{p}=0.2459$ for smoking cessation for active smokers reported at admission, $\mathrm{p}=0.3912$ for balanced diet for overweighted, diabetic or dyslipidaemic patients, and $\mathrm{p}=0.2198$ for lipid and glucose monitoring at 3 months and/or 6 months.

\section{DISCUSSION}

Concerning the pathways of care in the acute phase, the ESC 2017 guidelines recommended immediate 


\section{Pathways of care}

Management at the acute phase

\section{Life courses}

Follow-up at 12 months post-STEMI

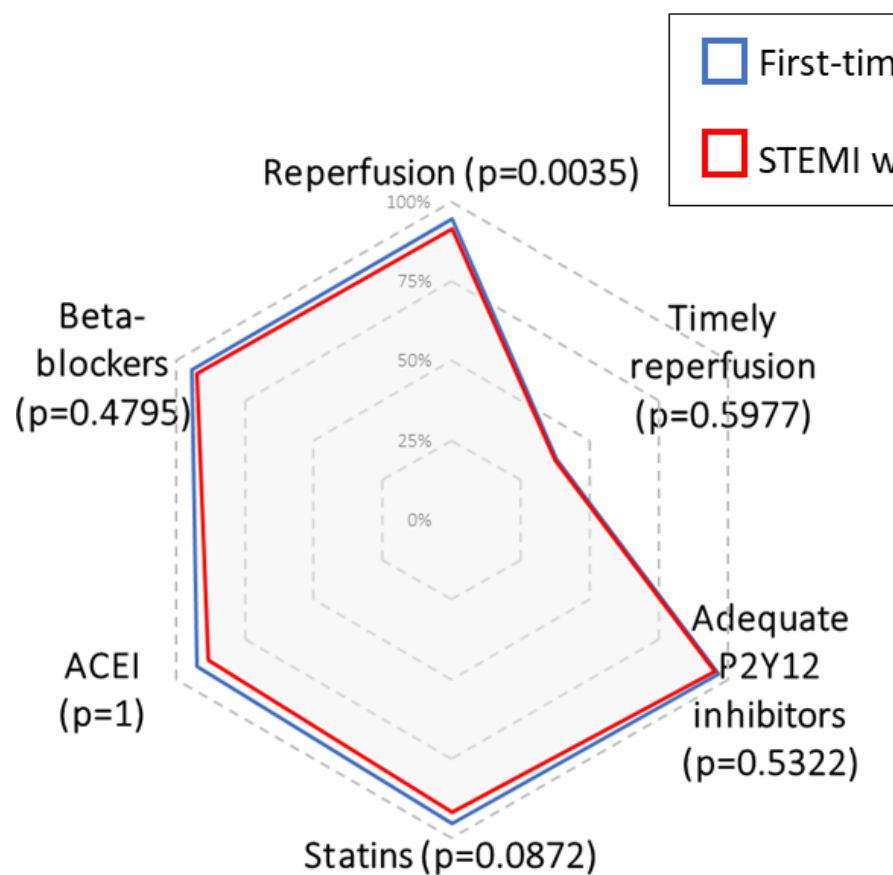

Figure 3 Radar plots for the pathways of care in the acute phase (reperfusion among eligible patients, timely reperfusion among eligible patients, adequate $\mathrm{P}_{2} \mathrm{Y}_{12}$ inhibition during hospitalisation, statins at discharge, Angiotensin Converting Enzyme Inhibitors (ACEls) at discharge among patients with heart failure, beta-blockers at discharge among patients with heart failure and dual antiplatelet therapy) and the life courses within 12 months of follow-up (12-month adherence to BASIC treatment, cardiac rehabilitation programme, daily physical activity, smoking cessation for active smokers, balanced diet for overweight, diabetes and dyslipidaemic patients, and lipid and glucose monitoring at 3 months and/or 6 months) based on matching analysis. BASIC, beta-blocker, anti-platelet therapy, statin and converting enzyme inhibitor; MI, myocardial infarction; STEMI, ST-elevated myocardial infarction.

angiography in cases of STEMI with prior MI. In this study, we noticed only 26/5423 patients with first-time STEMI and 4/883 patients with STEMI with prior MI who did not undergo coronarography probably because of their advanced age, comorbidities and risk of major bleeding. Also, we observed a lower PCI rate for the STEMI with prior MI compared with first-time STEMI. This difference may be partly explained by a higher rate of coronary revascularisation surgery (45/315 (14.3\%) vs $14 / 85(16.5 \%), \mathrm{p}=0.7484)$ or a higher rate of in-hospital mortality after coronarography $(31 / 315(9.8 \%)$ vs $14 / 85(16.5 \%), \mathrm{p}=0.1277)$ in the STEMI with prior MI group. Based on the recommended quality indicators, we observed a small margin of improvement in the acute phase, except for the timely reperfusion for first-time STEMI and STEMI with prior MI.

Concerning the life courses within 1 year after STEMI, the patients with first time STEMI were less compliant to treatments at 1-year follow-up, but they seem more compliant to lifestyle changes. The literature stated that survivors of STEMI remained at high long-term risk of recurrent ischaemic cardiovascular events ${ }^{20}$ and mortality, and demonstrated the effectiveness of patient education in decreasing the risk with changing the key lifestyle habits in particular smoking cessation ${ }^{22}$ and control of the high density lipoproteinlevel. ${ }^{21}$ The literature has also highlighted that secondary prevention strategies after a STEMI episode are still far from being optimal ${ }^{23}$ and also denoted substantial problem of guidance documents for clinicians. ${ }^{24}$ These results potentially counterbalance the prognostic benefits of the reperfusion therapy. Literature also suggested the need to integrate post-discharge health support with cardiac rehabilitation to facilitate recovery after primary PCI ${ }^{25}$ with post-discharge home visits at 4 weeks and at 6 months for instance. In this study, we observed that one-third of patients were discharged home within 48 hours after STEMI, which tends to trivialise the MI and suggests that patients were probably not receptive to the prevention messages. And as mentioned in the literature, the existence of the "healthy adherer"12 should also probably be considered.

Further investigations are required to identify the reasons for non-adherence to secondary prevention and to propose appropriate responses to clinicians and patients. Our findings should also make us focus on the possibility to propose post-discharge health support to increase the adherence to key lifestyle interventions, and thus facilitate recovery and reduce reinfarction and mortality. Another investigation field concerns the impact of living in rural and urban geographical area on the recovery. ${ }^{26}$ 


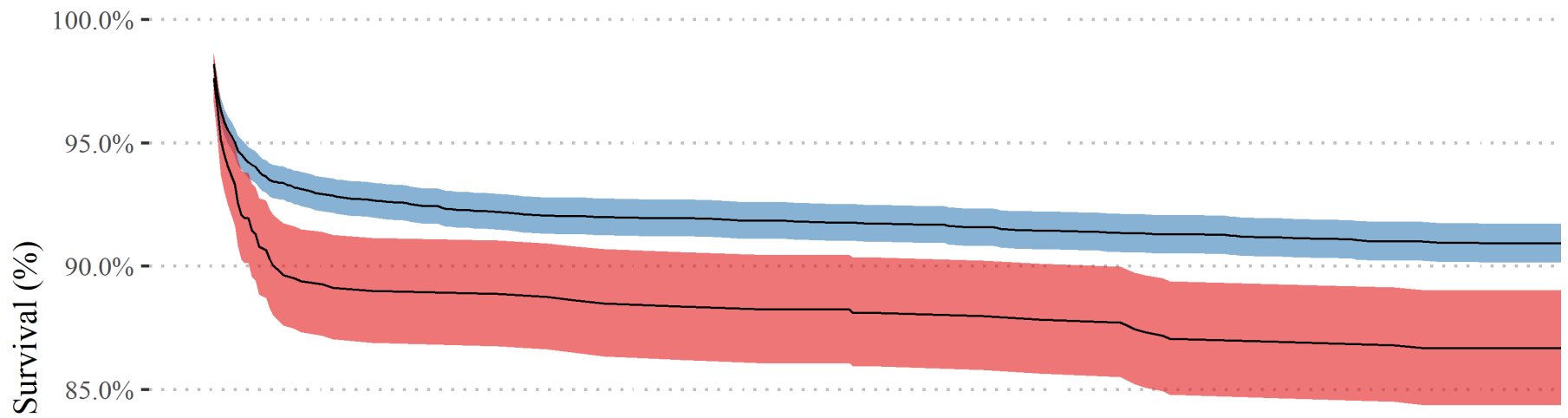

$$
\begin{aligned}
\text { Unadjusted } p & =0.0001 \\
80.0 \%-\ldots \ldots \text { Adjusted } p & =0.0609
\end{aligned}
$$

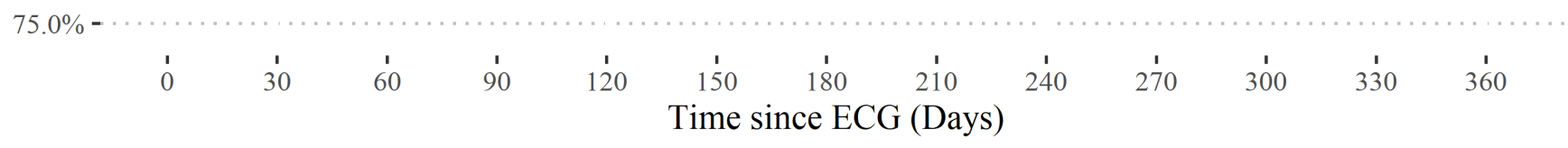

Figure 4 Kaplan-Meier survival curves of mortality at 1 month, 6 months and 1 year post-qualifying ECG. MI, myocardial infarction; STEMI, ST-elevated myocardial infarction.

The 2019 AHA recommendations concluded that education programmes must consider patients' health literacy, education levels and motivations to improve their lifestyle habits. ${ }^{27}$ One of the key goals also included the consideration of the cost and value for enhancing the overall value of the delivery of cardiovascular care.

With $88.52 \%$ of patients with STEMI being followed-up at 1 year, we brought a substantial added value with respect to the main challenges in secondary prevention. ${ }^{13}$ However, several limitations should be mentioned. First, data about clinical history (eg, cancer or chronic obstructive pulmonary disease) and coronary atherosclerotic involvement (eg, left main or multivessel disease, syntax score, chronic total occlusion and incomplete revascularisation) were not collected in the Registry and could have a prognostic value in the 1-year follow-up. Also, we cannot determine the role of secondary prevention in the 1-year mortality or reinfarction rates, because the key lifestyle interventions were collected for patients who were alive at 1 year after PCI discharge. Second, the date of reinfarction was not collected during the 1-year follow-up, preventing a survival analysis and a multivariate analysis to determine the role of secondary prevention in reinfarction and/or mortality.

\section{CONCLUSION}

The OSCAR registry provided an exhaustive overview of real-life clinical practices conditions for the management of STEMI in the acute phase and during the 1-year life courses. There was no significant difference in terms of delays and reperfusion strategies between first-time STEMI and STEMI with prior MI. STEMI with prior MI presented an optimised use of prehospital resources, probably due to their previous experience. But nearly one half of survivors did not observe the secondary prevention programme with low adherence to BASIC treatment and to the recommended lifestyle behaviours.

\section{Author affiliations}

${ }^{1}$ RESCUe-RESUVal network, Hospital Center Lucien Hussel, Vienne, France ${ }^{2}$ Laboratory Systemic Health Care, EA 4129, University of Lyon 1, Lyon, France ${ }^{3}$ Department of Emergency Medicine and SAMU, Hospital Edouard Herriot, Hospices Civils de Lyon, Lyon, France

${ }^{4}$ HESPER EA 7425, Claude Bernard Lyon 1 University, Lyon, France ${ }^{5}$ Cardiology intensive care unit, Hospital Louis Pradel, Groupement Hospitalier Est, Hospices Civils de Lyon, Bron, France

${ }^{6}$ Clinical Research Unit and Emergency Department, Médipôle Lyon-Villeurbanne, Villeurbanne, France

Collaborators On behalf of the RESCUe Research Group: Dr Christophe Robin (Clinique Convert, Bourg en Bresse), Dr Xavier Tchenio (Hôpital Fleyriat, Bourg en Bresse), Dr Pierre Lantelme (Hôpital Nord-ouest site Villefranche), Dr Pierre Lantelme (HCL Groupement Hospitalier Nord, Lyon 4), Pr Eric Bonnefoy-Cudraz (HCL, Groupement Hospitalier Est Hôpital L Pradel-Bron), Dr Jean-Philippe Claudel (Infirmerie Protestante, Caluire-Cuire), Dr Alain Hepp (Clinique la Sauvegarde, Lyon 9), Dr Thibault Perret (Centre Hospitalier Saint Joseph-Saint luc, Lyon 7), Dr Didier Champagnac (Médipôle Privé, Villeurbanne) and Dr Philippe Chapon (Centre Hospitalier de Valence).

Contributors LF drafted the manuscript and develop methodology., OK interpreted the results. CC provided statistical analysis. NE and AP collected the data. KT, EB-C and $\mathrm{CD}$ provided critical readings. CEK supervised the work.

Funding The RESCUe Network is funded by the Regional Agency for Health from Auvergne-Rhône-Alpes region (Agence Régionale de Santé Auvergne-Rhône-Alpes). Grant/Award: not applicable. 
Competing interests None declared.

Patient and public involvement Patients and/or the public were not involved in the design, or conduct, or reporting, or dissemination plans of this research.

Patient consent for publication Not required.

Provenance and peer review Not commissioned; externally peer reviewed.

Data availability statement Data are available upon reasonable request.

Open access This is an open access article distributed in accordance with the Creative Commons Attribution Non Commercial (CC BY-NC 4.0) license, which permits others to distribute, remix, adapt, build upon this work non-commercially, and license their derivative works on different terms, provided the original work is properly cited, appropriate credit is given, any changes made indicated, and the use is non-commercial. See: http://creativecommons.org/licenses/by-nc/4.0/.

\section{ORCID iD}

Laurie Fraticelli http://orcid.org/0000-0002-2647-658X

\section{REFERENCES}

1 Puymirat E, Simon T, Steg PG, et al. Association of changes in clinical characteristics and management with improvement in survival among patients with ST-elevation myocardial infarction. JAMA 2012;308:998-1006.

2 Hermann M, Witassek F, Erne P, et al. Impact of cardiac rehabilitation referral on one-year outcome after discharge of patients with acute myocardial infarction. Eur J Prev Cardiol 2019;26:138-44.

3 Pedersen F, Butrymovich V, Kelbæk H, et al. Short- and long-term cause of death in patients treated with primary PCl for STEMI. $J$ Am Coll Cardiol 2014;64:2101-8.

4 Fokkema ML, James SK, Albertsson P, et al. Population trends in percutaneous coronary intervention: 20-year results from the SCAAR (Swedish coronary angiography and angioplasty registry). J Am Coll Cardiol 2013;61:1222-30.

5 Kristensen SD, Laut KG, Fajadet J, et al. Reperfusion therapy for ST elevation acute myocardial infarction 2010/2011: current status in 37 ESC countries. Eur Heart J 2014;35:1957-70.

6 Benhorin J, Moss AJ, Oakes D. Prognostic significance of nonfatal myocardial reinfarction. multicenter diltiazem postinfarction trial Research Group. J Am Coll Cardiol 1990;15:253-8.

7 Kikkert WJ, Hoebers LP, Damman P, et al. Recurrent myocardial infarction after primary percutaneous coronary intervention for ST-segment elevation myocardial infarction. Am J Cardiol 2014;113:229-35.

8 Tian L, Yang Y, Zhu J, et al. Impact of previous stroke on short-term myocardial reinfarction in patients with acute ST segment elevation myocardial infarction: an observational multicenter study. Medicine 2016;95:e2742.

9 Hara M, Sakata Y, Nakatani D, et al. Reduced risk of recurrent myocardial infarction in homozygous carriers of the chromosome 9p21 rs1333049 $\mathrm{C}$ risk allele in the contemporary percutaneous coronary intervention era: a prospective observational study. BMJ Open 2014;4:e005438.

10 Westerhout CM, Bonnefoy E, Welsh RC, et al. The influence of time from symptom onset and reperfusion strategy on 1-year survival in ST-elevation myocardial infarction: a pooled analysis of an early fibrinolytic strategy versus primary percutaneous coronary intervention from CAPTIM and West. Am Heart J 2011;161:283-90.

11 Ibanez B, James S, et al, ESC Scientific Document Group. Esc guidelines for the management of acute myocardial infarction in patients presenting with ST-segment elevation: the task force for the management of acute myocardial infarction in patients presenting with ST-segment elevation of the European Society of cardiology (ESC). Eur Heart J 2017;2018:119-77.

12 Simpson SH, Eurich DT, Majumdar SR, et al. A meta-analysis of the association between adherence to drug therapy and mortality. BMJ 2006;333:15

13 Piepoli MF, Corr U, Abreu A, et al. Cardiac Rehabilitation Section of the European Association for Cardiovascular Prevention \& Rehabilitation of the ESC. Challenges in secondary prevention of cardiovascular diseases: a review of the current practice. Int $J$ Cardiol 2015;180:114-9.

14 El Khoury C, Bochaton T, Flocard E, et al. Observatoire des syndromes Coronaires Aigus dans rescue (OSCAR) research team. five-year evolution of reperfusion strategies and early mortality in patients with ST-segment elevation myocardial infarction in France. Eur Heart J Acute Cardiovasc Care 2017;6:573-82.

15 von Elm E, Altman DG, Egger M, et al. The strengthening the reporting of observational studies in epidemiology (STROBE) statement: guidelines for reporting observational studies. Int J Surg 2014;12:1495-9.

16 Kohli P, Wallentin L, Reyes E, et al. Reduction in first and recurrent cardiovascular events with ticagrelor compared with clopidogrel in the Plato study. Circulation 2013;127:673-80.

17 Grimaldi-Bensouda L, Danchin N, Dallongeville J, et al. Effectiveness of new antiplatelets in the prevention of recurrent myocardial infarction. Heart 2018;104:1583-92.

18 Schiele F, Gale CP, Bonnefoy E, et al. Quality indicators for acute myocardial infarction: a position paper of the acute cardiovascular care association. Eur Heart J Acute Cardiovasc Care 2017;6:34-59.

19 Austin PC. The use of propensity score methods with survival or time-to-event outcomes: reporting measures of effect similar to those used in randomized experiments. Stat Med 2014;33:1242-58.

20 Huynh T, Montigny M, Iftikhar U, et al. Recurrent cardiovascular events in survivors of myocardial infarction with ST-segment elevation (from the AMI-QUEBEC study). Am J Cardiol 2018;121:897-902.

21 Sakakura K, Kubo N, Ako J, et al. Clinical features of early recurrent myocardial infarction. Heart Vessels 2009;24:347-51.

22 Siudak Z, Krawczyk-Ożóg A, Twarda I, et al. "Heart without smoke" educational campaign - the role of patient education in secondary prevention of cardiovascular disease. Kardiol Pol 2018;76:125-9.

23 Ribas N, García-García C, Meroño O, et al. Secondary prevention strategies after an acute ST-segment elevation myocardial infarction in the AMI code era: beyond myocardial mechanical reperfusion. BMC Cardiovasc Disord 2017;17:54.

24 Abell B, Glasziou P, Hoffmann T. Exploration of the methodological quality and clinical usefulness of a cross-sectional sample of published guidance about exercise training and physical activity for the secondary prevention of coronary heart disease. BMC Cardiovasc Disord 2017;17:153.

25 Soo Hoo SY, Gallagher R, Elliott D. Predictors of cardiac rehabilitation attendance following primary percutaneous coronary intervention for ST-elevation myocardial infarction in Australia. Nurs Health Sci 2016;18:230-7.

26 Hamilton S, Mills B, McRae S, et al. Evidence to service gap: cardiac rehabilitation and secondary prevention in rural and remote Western Australia. BMC Health Serv Res 2018;18:64.

27 Arnett DK, Blumenthal RS, Albert MA, et al. ACC/AHA guideline on the primary prevention of cardiovascular disease: a report of the American College of Cardiology/American heart association Task force on clinical practice guidelines. J Am Coll Cardiol 2019;2019:e177-232. 